\title{
Aberrant mRNA splicing generates oncogenic RNA isoforms and contributes to the development and progression of cholangiocarcinoma (Review)
}

\author{
JUTHAMAS YOSUDJAI $^{1}$, SOPIT WONGKHAM ${ }^{2}$, SIWANON JIRAWATNOTAI ${ }^{3}$ and WORASAK KAEWKONG ${ }^{1}$ \\ ${ }^{1}$ Department of Biochemistry, Faculty of Medical Science, Naresuan University, Phitsanulok 65000; \\ ${ }^{2}$ Department of Biochemistry, Faculty of Medicine, Khon Kaen University, Khon Kaen 40002; \\ ${ }^{3}$ Siriraj Center for Research of Excellence (SiCORE) for System Pharmacology, Department of Pharmacology, \\ Faculty of Medicine, Siriraj Medical School, Mahidol University, Bangkok 10700, Thailand
}

Received October 2, 2018; Accepted January 4, 2019

DOI: $10.3892 /$ br.2019.1188

\begin{abstract}
Cholangiocarcinoma is a lethal biliary cancer, with an unclear molecular pathogenesis. Alternative splicing is a post-transcriptional modification that generates mature mRNAs, which are subsequently translated into proteins. Aberrant alternative splicing has been reported to serve a role in tumor initiation, maintenance and metastasis in several types of human cancer, including cholangiocarcinoma. In this review, the aberrant splicing of genes and the functional contributions of the spliced genes, in the carcinogenesis, progression and aggressiveness of cholangiocarcinoma are summarized. In addition, factors that influence this aberrant splicing that may be relevant as therapeutic targets or prognosis markers for cholangiocarcinoma are discussed.
\end{abstract}

\section{Contents}

1. Introduction

2. Relevance of aberrant alternative splicing in cholangiocarcinoma development, progression and the aggressiveness of phenotypes

3. Targeting aberrant splicing as a novel approach for cancer treatment

4. Conclusion

Correspondence to: Dr Worasak Kaewkong, Department of Biochemistry, Faculty of Medical Science, Naresuan University, 99 Moo 9 Siharajdachochai Road, Phitsanulok 65000, Thailand E-mail: worasakk@nu.ac.th

Key words: cholangiocarcinoma, alternative splicing, spliced gene

\section{Introduction}

Cholangiocarcinoma (CCA), is a malignant tumor that arises from the biliary epithelial tissue and is highly aggressive, with no effective pharmacological treatment available. This cancer has a poor prognosis and a high mortality rate (1). The highest worldwide incidence of CCA is found in the North and Northeast of Thailand, at $\sim 85$ cases per 100,000 individuals per year (2). The major predisposing factors for CCA in Asia are infection by the liver fluke, Opisthorchis viverrini $(3,4)$ and exposure to groups of food-borne carcinogens, especially $\mathrm{N}$-nitrosodimethylamine compounds identified in grilled or fermented foods (5). The only effective treatment for the disease is surgery. For patients who are not eligible for surgical therapy, gemcitabine- or 5-fluoro-uracil (FU)-based treatments are given. These are largely ineffective, since the response rate is only $20-30 \%$.

The molecular pathology of bile duct cancer has been a topic of intense study. The molecular pathogenesis of CCA usually involves abnormal signal transduction and pro-inflammatory secretion, facilitated by gene mutations and epigenetic dysregulations (on a set of oncogenes and tumor suppressor genes) (6). Several lines of evidence also indicate that the abnormal expression of growth factors and receptors, the RAS/RAF/ dual specificity mitogen-activated protein kinase kinase 1 pathway, and the phosphatidylinositol 3 kinase $(\mathrm{PI} 3 \mathrm{~K}) /$ protein kinase $\mathrm{B}(\mathrm{AKT}) /$ mammalian target of rapamycin pathway may be involved with CCA initiation, maintenance, and metastasis (7). Several studies reported that specific-target drugs or inhibitors, including epithelial growth factor receptor (EGFR; Lapatinib or Erlotinib), fibroblast (F) GFR and PI3K inhibitor, (8) may be applicable to CCA. A number of novel therapeutics are under evaluation in a phase 2 study (9).

Alternative splicing (AS) is a post-transcription modulation process that can generate a variety of gene isoforms. Spliced mRNA is able to be translated to differential amino acids with various biological functions (10). Pre-mRNA is spliced through the spliceosome; a large macromolecule comprising 5 small nuclear ribonucleoproteins (snRNPs U1, U2, U4/U6 and 
U5). The AS generates 5 common splicing patterns, including alternative 5' splice site, alternative 3' splice site, exon skipping, intron retention and mutually exclusive exons. Previous data demonstrates that aberrant alternative splicing also includes exonic regulatory element mutation, splice site mutation and altered splice isoform ratios. The differential expression of splicing factors is implicated in various diseases and linked to hallmarks of cancer (11-15). A number of reports demonstrated a correlation between aberrant AS and tumor initiation/progression (16-20). The truncated oncogenic forms of the proteins, resulted from aberrant AS involved in cancer cell growth, apoptosis, drug resistance and angiogenesis.

Aberrant splicing of macrophage-stimulating protein receptor (RON) (21) and Racl (22) promoted angiogenesis and epithelial mesenchymal transition (EMT) phenotypes. In addition, a BRAF (V600E) spliced isoform, lacking exon 4-8 induced vemurafenib drug resistance in melanoma (23). In the present review, evidence is presented that supports important roles for aberrant splicing and the spliced isoforms of the genes, in CCA carcinogenesis and cancer aggressiveness.

\section{Relevance of aberrant AS in cholangiocarcinoma development, progression and aggressiveness of phenotypes}

A number of articles have summarized the interconnection between AS and cancer progression, including 17 genes in lung cancer (16), 2 reports in breast cancer in which 7 genes (17) and 9 genes (18), respectively were demonstrated, and 9 genes in hepatocellular carcinoma $(19,20)$. The global cancer-specific transcript variants of five cancers demonstrated protein metabolism and modification are the most prevalent functional processes in cancer (24). As mentioned previously, aberrant AS has been discovered and proven to have functional involvement in the initiation and progression of cancer. In CCA, 623 genes presented with alternative splicing in CCA samples when compared with healthy bile duct tissue samples (25). In this review, atypical splicing of nine genes, which have been investigated at the in vitro, in vivo and clinical levels, and their relevance to CCA pathogenicity are summarized. The structure of nine pre-mRNAs that undergo alternative mRNA splicing to generate wild-type mRNA or variant transcripts are presented in Fig. 1. The derived-spliced transcripts or protein isoforms are summarized by how they can facilitate various characteristics of a cancer cell, as presented in Fig. 2 and Table I.

Cluster of differentiation (CD)44v6 and CD44v8-10. CD44 is a transmembrane glycoprotein receptor that specifically binds to extracellular hyaluronan and other extracellular matrix $(\mathrm{ECM})$ proteins to activate signal transduction, and serves important roles in tumor proliferation, migration, and invasion $(26,27)$. CD44 pre-mRNA encodes transmembrane and cytoplasmic-tail regions. The AS of CD44 can generate up to 12 isoforms of proteins with different biological functions. The $\mathrm{CD} 44 \mathrm{v}$ isoforms participate in cancer progression: CD44v6 promotes EMT and activates the transforming growth factor $\beta$ pathway $(28,29)$, and CD44v8-10 is involved in poor cancer prognosis $(30,31)$. Expression of CD44v6 can be linked to CCA proliferation. CD44v6 is a CCA-specific isoform that has never been detected in normal bile ducts (32). Furthermore, the CD44v8-10 transcript was overexpressed in CCA and was demonstrated to stabilize the XCT system, a cysteine/glutamate transporter, to elevate glutathione synthesis and inhibit reactive oxygen species (ROS) accumulation in CCA cells. This function of CD44v8-10 was demonstrated to facilitate cancer cell survival in cases caused by liver fluke-induced inflammation. In addition, upregulation of CD44v8-10 suppressed p38 mitogen-activated protein kinase 1 (MAPK), which is a signaling protein involved in ROS suppression. Although the mechanism by which the CD44 spliced isoform may suppress p38 is still unclear, this observation appeared to be clinically relevant, since patients with CD44v overexpression and negative-phosphorylated (phospho)-p38MAPK have significantly shorter survival times compared with low CD44v expression and positive-phospho-p38(MAPK) (33).

WISPIv. Wnt-inducible secreted protein 1 [(WISP1) also known as $\mathrm{CNN} 4]$ is a member of the cysteine-rich $\mathrm{CCN}$ family of proteins, which are highly expressed in skeletal tissues and has a role in bone formation and maintenance. Functions of this protein involve cell proliferation, osteoblastic differentiation and migration $(34,35)$. WISP1 comprises 4 domains, including insulin-like growth factor-binding protein (IGFBP), VWC, thrombospondin-1 (TSP-1) and CT domains and is known to have variants with biological functions. A WISP1 variant lacking exon 3 (WISP1v) loses its VWC domain, which is thought to participate in protein complex formation. Ectopic expression demonstrated that the WISP1v is a secreted oncoprotein, which drives cellular transformation and rapid cumulative growth. WISP1v overexpression enhanced the invasive phenotype in gastric carcinoma cells, while wild-type WISP1 exhibited no such potential. These findings suggested that the $\mathrm{CCN}$ protein WISP1v was involved in the aggressive progression of scirrhous gastric carcinoma (36). In CCA, the aberrant isoform WISPlv was demonstrated to be overexpressed in patient CCA tissues (37). Furthermore, upregulation of WISP1v was associated with shorter overall survival time among patients following surgical treatment (38). In addition, WISP1v was demonstrated to promote cell invasion in vitro and this process was demonstrated to be mediated by p38 MAPK (37).

Nek2A and Nek2B. Nek2, or NIMA-related kinase 2, is a serine/ threonine kinase that regulates cell division through centrosome separation (39). The spliced isoform of Nek consists of three forms, Nek2A, Nek2B and Nek2A-T (40). Isoforms of NEK are demonstrated to be functionally involved with cancer formation. In patients, overexpression of Nek2a was associated with Ki-67 expression, a cell proliferation marker (41). In addition, NEK2A cytoplasmic expression was positively associated with cancer grade and tumor size in breast invasive ductal carcinoma and metastatic potential (42). Cancer cells overexpressing the NEK2A isoform demonstrated a significant increase in colony formation compared with control cells and small interfering (si)RNA-based depletion of NEK2a resulted in the halting of cancer cell proliferation (43). Nek2A/Nek2A-T were demonstrated to be highly upregulated in CCA cell lines, with the predominant isoform being Nek2A/Nek2A-T and Nek2B being the lesser expressed isoform (44). Furthermore, the expression of Nek2B was demonstrated to positively correlate with proliferation potential in breast cancer cells (45). 


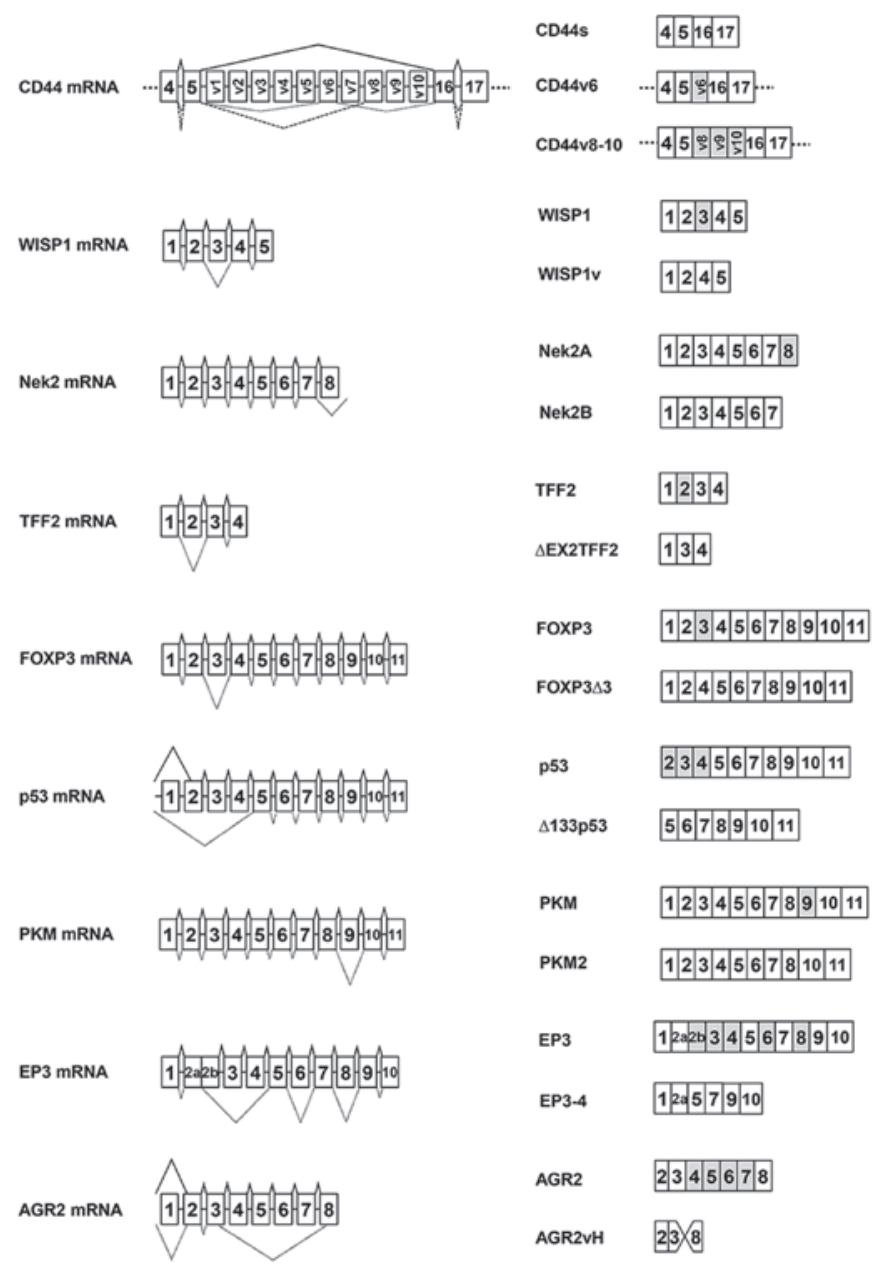

Figure 1. Schematic representation of the alternative splicing events implicated in cholangiocarcinoma development and progression. Exons are represented by boxes and introns by lines. Continuous lines represent the exon inclusion for wild-type mRNA, whereas dotted lines represent the exon inclusion for spliced transcripts. Skipped or included exons from alternative splicing, that differ from wild-type mRNA, are presented in gray.

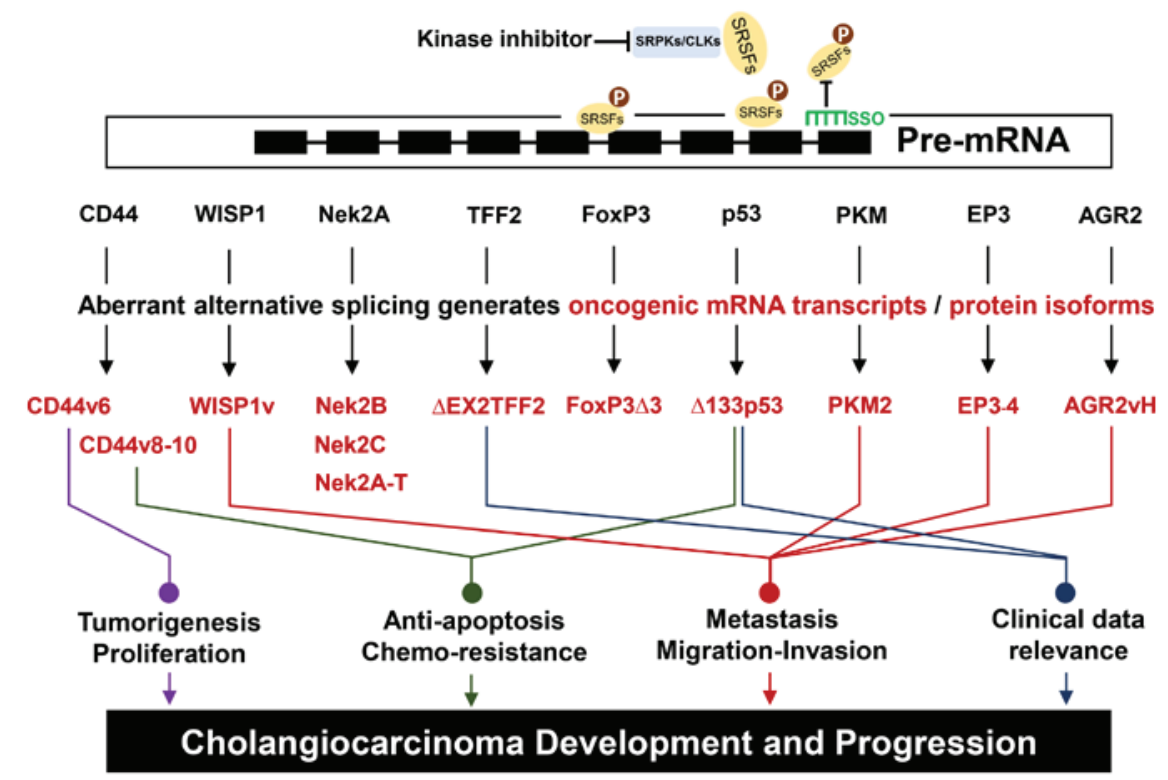

Figure 2. Spliced mRNA transcripts and their functions in cholangiocarcinoma.

$\triangle E X 2 T F F 2$. Trefoil factor 2 (TFF2) is a secreted protein that serves important roles in gastrointestinal restitution (46), chronic kidney disease and pulmonary inflammation, through the induction of cell migration and proliferation. Overexpression of TFF2 
Table I. Spliced mRNA transcripts and their functions in cholangiocarcinoma.

\begin{tabular}{|c|c|c|c|c|c|}
\hline Author, year & Gene & $\begin{array}{l}\text { Spliced transcript/ } \\
\text { isoform }\end{array}$ & $\begin{array}{l}\text { Splicing } \\
\text { variants }\end{array}$ & Function & (Refs.) \\
\hline Yun et al, 2002 & CD44 & CD44v6 & Retained exon v6 & Proliferation & (32) \\
\hline Thanee et al, 2016 & CD44v8-10 & $\begin{array}{l}\text { Retained exon } \\
\text { v8-10 }\end{array}$ & Anti-apoptosis & & (33) \\
\hline Tanaka et al, 2003 & $\begin{array}{l}\text { Wnt-inducible secreted } \\
\text { Protein }\end{array}$ & WISP1v & $\begin{array}{l}\text { Skipping } \\
\text { exon } 3\end{array}$ & $\begin{array}{l}\text { Neural and } \\
\text { lymphatic } \\
\text { invasion }\end{array}$ & (37) \\
\hline Kokuryo et al, 2007 & $\begin{array}{l}\text { Serine/threonine- } \\
\text { protein kinase Nek2 }\end{array}$ & Nek2B & $\begin{array}{l}\text { Skipping } \\
\text { exon } 8\end{array}$ & $\begin{array}{l}\text { Function } \\
\text { unknown }\end{array}$ & (44) \\
\hline Kamlua et al, 2012 & Trefoil factor 2 & $\triangle \mathrm{EX} 2 \mathrm{TFF} 2$ & $\begin{array}{l}\text { Skipping } \\
\text { exon } 2\end{array}$ & $\begin{array}{l}\text { Independent } \\
\text { prognostic marker }\end{array}$ & (48) \\
\hline Harada et al, 2012 & Forkhead box protein 3 & Foxp $3 \Delta 3$ & Skipping exon 3 & Function unknown & (50) \\
\hline $\begin{array}{l}\text { Nutthasirikul et al, } \\
2013\end{array}$ & Tumor protein 53 & $\Delta 133 \mathrm{p} 53$ & Exon 1-4 skipping & $\begin{array}{l}\text { Independent } \\
\text { prognostic marker }\end{array}$ & (60) \\
\hline $\begin{array}{l}\text { Nutthasirikul et al, } \\
2015\end{array}$ & & & & $\begin{array}{l}\text { 5-Fluorouracil } \\
\text { resistance }\end{array}$ & (61) \\
\hline Yu et al, 2015 & Pyruvate kinase & PKM2 & $\begin{array}{l}\text { Mutually } \\
\text { exclusive exons; } \\
\text { exon } 9 \text { skipping and } \\
\text { exon } 10 \text { retention }\end{array}$ & $\begin{array}{l}\text { Neural } \\
\text { invasion }\end{array}$ & (67) \\
\hline Du et al, 2015 & E prostanoid receptor 3 & EP3-4 & $\begin{array}{l}\text { Exon } 2 b, 3,4,6 \\
\text { and } 8 \text { skipping }\end{array}$ & $\begin{array}{l}\text { Proliferation } \\
\text { migration } \\
\text { and invasion }\end{array}$ & (71) \\
\hline Yosudjai et al, 2018 & Anterior Gradient-2 & AGR2vH & $\begin{array}{l}\text { Alternative } 3^{\prime} \text { and } 5^{\prime} \\
\text { splice site and exon } \\
4-7 \text { skipping }\end{array}$ & $\begin{array}{l}\text { Migration, } \\
\text { invasion and } \\
\text { adhesion }\end{array}$ & (74) \\
\hline
\end{tabular}

is commonly identified in several types of cancer, implicating it in carcinogenesis. TFF2 was reported to exert its pro-proliferative activity through the EGFR-MAPK pathway in CCA (47). Previously, $\triangle \mathrm{EX} 2 \mathrm{TFF} 2$, an exon 2- skipping isoform of TFF2 with a stop codon (TAG) at exon 1 , was uncovered as a spliced isoform of TFF2 (48). Although, the roles of this transcript have not been clarified, the present study demonstrated that a high expression ratio of $\triangle \mathrm{EX} 2 \mathrm{TFF} 2 / \mathrm{wtTFF} 2$ in patients was significantly associated with a longer survival time (48). Therefore, the spliced isoform may act as a dominant-negative form of TFF2 that counteracts the cancer promoting wtTFF2 activity in CCA.

Forkhead box protein 3 (FOXP3 3 ). FOXP3 is a transcription factor in the forkhead protein family that is involved in $\mathrm{CD} 25^{+}$ regulatory $\mathrm{T}$ cell (Treg) development. Not only does FOXP3 control Treg development, it is also expressed in colorectal cancer cells, which is associated with poor prognosis in patients (49). Exon 3 skipping of FOXP3, resulting in an amino acid frameshift, has been reported in CCA (50). In addition, a FOXP3 splice isoform was also observed in melanoma cells, suggesting it has a role in suppressing immune activity (51).

$\Delta 133 p 53$. Tumor protein 53 (TP53 or p53) is one of the most important tumor suppressors, indicated by its high mutation rate across all types of cancer. p53 responds to various stress signals and orchestrates processes including cell cycle arrest, DNA repair, cellular senescence and apoptosis in response to specific stress signals (52). AS generates 12 p53 isoforms, including Tap53, $\Delta 40$ p53, $\Delta 133$ p53 and $\Delta 160$ p53 among others $(53,54)$. The differential regulation of $\mathrm{p} 53$ isoforms promotes the aggressiveness of several types of cancer. A study demonstrated that $\Delta 133 \mathrm{p} 53 \mathrm{~b}$ enhanced breast cancer 
stemness (55) and protected colorectal cells from camptothecin-induced apoptosis (56).

p53 has been identified as a gene that frequently mutates in a large number of CCA cases (57-59), suggesting that a perturbed p53 pathway facilitates CCA carcinogenesis. A study demonstrated that a high $\Delta 133 \mathrm{p} 53 / \mathrm{p} 53$ mRNA expression ratio correlates with a poor overall survival (60). Notably, $\Delta 133 p 53$ is also associated with resistance to certain cancer drugs; an association between $\Delta 133 \mathrm{p} 53$ and 5-FU-resistance in CCA cells was demonstrated, and $\Delta 133$ p53 was upregulated in 5-FU-resistant tumor tissues and CCA cell lines in a dose-dependent manner (61). Given that 5-FU is a cytotoxic drug that interferes with DNA synthesis, the $\Delta 133$ p53 isoform may act as a dominant-negative p53 that interferes with the activity of wtp53 in the ternary complex (62). Accordingly, suppression of $\Delta 133 \mathrm{p} 53$ promoted apoptosis, which correlated with an upregulation of pro-apoptotic Bax and a downregulation of anti-apoptotic Bcl-2 (61).

Pyruvate kinase (PKM2). PKM is a rate-limiting enzyme that catalyzes the conversion of phosphoenolpyruvate to pyruvate during glycolysis. PKM can be generated in 4 isoforms, which are expressed differently in various tissues. One of the isoforms is PKM2, which lacks exon 9 and is a major isoform highly expressed in a number of types of cancer (63). Previously data demonstrate that overexpression of PKM2 is linked to tumor growth, metastasis capability and a poor prognosis in hepatocellular carcinoma, pancreatic ductal adenocarcinoma and gallbladder cancer (64-66). In hilar cholangiocarcinoma, immunohistochemical staining specific to the PKM2 isoform demonstrated a great number of positive-staining cells in the tumor tissue. Patients with high-PKM2-expressing tumors exhibited a higher rate of tumor recurrence and a shorter overall survival time, when compared with patients with low PKM2 expression. However, there is still no conclusive evidence that indicates PKM2 is a cancer driver for CCA. In addition, PKM2 elevation was associated with CCA development and neural invasion (67).

EP3-4. E prostanoid receptor 3 (EP3), or prostaglandin E2 receptor 3 (PTGER3), is a member of a $G$ protein-coupled receptor family, that specifically binds to prostaglandin E2 (PGE2) to activate various responses.EP3 receptor can generate up to 11 spliced isoforms. Previous data demonstrate that EP3-5 and EP3-6 isoforms were associated with cell proliferation in the myometrium in humans (68). Furthermore, overexpression of the EP3-4 receptor promoted cell growth through upregulating FUSE-binding protein 1 in liver cancer (69). In CCA, the truncated EP3-4 isoform, which includes exon 1, 2a, 5 and 10, was detected (70). This EP3-4 isoform is activated through the Src/EGFR/PI3K/AKT/glycogen synthase kinase-3 $\beta$ pathway and promotes cell proliferation, migration, and invasion. This results in enhanced expression of the downstream proteins c-Myc and snail. Therefore, it is believed to serve a regulatory role in CCA cell growth and metastasis (71).

Anterior Gradient-2 (AGR2)vH. The expression profiling of metastasis-associated genes in CCA demonstrated that AGR2 is one of the most-upregulated genes, specific to the metastatic CCA cell line, when compared with the parental cell line (72).
The AGR2 gene encodes for a disulfide isomerase enzyme, which is commonly expressed in mucus-secreting tissues. The mRNA splicing of AGR2 was first characterized in prostate cancer (PCa). Spliced isoforms include AGR2vC, AGR2vE, AGR2vF, AGR2vG and AGR2vH. Among the 5 spliced isoforms and the wild-type, AGR2vG and AGR2vH were demonstrated to be significantly upregulated in the exosome from patient's urine sample analysis. These two exhibited high diagnostic value, with higher sensitivity and specificity when compared with the prostate-specific antigen used as a standard clinical biomarker for PCa diagnosis (73). In CCA cell lines, AGR2 RNA isoforms, namely AGR2vE, AGR2vF and AGR2vH, were recently reported that are specific to metastatic CCA cells (74). It was demonstrated that the AGR2vH isoform enables various metastatic-associated phenotypes in CCA cells. Suppression of AGR2vH by the AGR2vH-specific siRNA significantly reduced CCA cell migration and invasion. Concordantly, AGR2vH overexpression promoted cell proliferation, migration, invasion and adhesion potential. In addition, it was demonstrated that the expression of AGR2vH influences metastasis-associated phenotypes through the upregulation of vimentin. Therefore, the results indicated that the metastasis-specific isoform AGR2vH serves an important role in cancer severity (74).

\section{Targeting aberrant splicing as a novel concept for cancer treatment}

The prominent role of the aberrant AS in carcinogenesis has been demonstrated, indicating that AS may be a good target for cancer therapy. Aberrant AS can be manipulated in several steps: For example, Pre-Trans-Splicing Molecule (PTM) is the artificial sequence that can reprogram mRNA through replacement of the 3 'exon, 5 'exon and internal exon $(75,76)$. The results demonstrated that the trans-splicing molecule reduced the number of mutant p53 transcripts in the transfected cells, which resulted in cell cycle arrest, apoptosis and tumor xenograft suppression with colorectal cancer and hepatocellular carcinoma cells $(77,78)$. However, the use of PTM for targeting oncogenic AS events is not yet well studied and the PTM modification has limitations for cancer treatment. Therefore, this review discussed the methodologies that may apply to cancer therapy, including small molecule splicing modulators and SSOs, each of which are currently under study in clinical trials.

Small molecules splicing modulators. Splicing factors are key molecules that influence AS regulation and are associated with cancer aggressiveness and pathological phenotypes (79). A previous report demonstrated that an overexpression of serine/arginine-rich splicing factor 1 (SRSF1) can facilitate abnormal splicing of tumor suppressors and proto-oncogenes (80). The results demonstrated that SRSF1 promotes $12 \mathrm{~A}$ inclusion of an isoform of BIN1, which interferes with the tumor-suppressing activity of this protein. In the same study, the researchers demonstrated an increase in S6K1 isoform 2 expression resulting from SRSF1 overexpression that was associated with colony formation activity (80). An Ov-infected hamster model was used to identify the differentially expressed genes to study 
the molecular mechanism of CCA carcinogenesis. The results demonstrated that SRSF9 is one of the genes that are overexpressed in Ov-infected hamsters and may be associated with CCA initiation (81).

Aberrant spliceosomal proteins are important factors associated with carcinogenesis. The data revealed that mutations in splicing factor 3B subunit 1A (SF3B1), which encodes the core component of U2 snRNP, is linked to erroneous 3' splice site selection (82-84). The results demonstrated that the SF3B1 K700E mutation led to differential splicing in uveal melanoma and breast cancer $(85,86)$. In addition, luminal B and progesterone receptor-negative breast cancer patients with additional SF3B1 mutations have significantly shorter survival times (87).

It is possible to modulate aberrant AS based on small molecule inhibitors of splicing factors or mutated spliceosomal proteins: For example, it has been demonstrated that a natural product 'Borrelidin' can bind to a splicing protein, FBP21, leading to a decrease of the vascular endothelial growth factor (VEGF) pro-angiogenic isoform and an increase of the VEGF anti-angiogenic isoform, in RPE cells (88). Previous studies demonstrated that a natural product, FR901464 and its methylated derivative, spliceostatin A, as well as E7107, specifically inhibit spliceosome assembly through SF3B1 and lead to halted splicing reactions (89-91). The results demonstrated that treatment of these small molecules inhibits cell cycle progression and inhibits the tumor angiogenesis through decreasing the levels of VEGF transcripts $(92,93)$.

Not only does the altered expression of splicing regulators affect AS, but the alteration of the phosphorylation status of the splicing factor/modulator was also implicated in cancer progression. In head and neck squamous cell carcinoma, hyperphosphorylation of SRPK2, a serine/arginine-rich protein-specific kinase that phosphorylates SRSF1/2, was detected in cancer cells; the phosphorylation promotes cell proliferation, migration and invasion (94). Alteration to the kinase alters the AS pattern. A previous study demonstrated that CLKs and SRSF protein kinases (SRPKs) are targets for kinase inhibitors to modulate AS; treatment with Cpd-1, Cpd-2, and Cpd-3 significantly reduced the levels of phosphorylated SR proteins, therefore affecting the splicing pattern of multiple genes and inducing cell apoptosis (95). Furthermore, the other kinase inhibitors, including ceramide, affect splice site selection of Bcl-x and increases pro-apoptotic isoforms through the dephosphorylation of the SR protein (96).

SSOs technology. SSOs are single-stranded nucleic acids, usually 15-25 bases, that are complementary to the mRNA target transcripts or the recognition sequence of the splice sites, that leads to modulated splicing. A number of studies demonstrated that SSO can inhibit aberrant RNA translation: I.e., MDM4 is the protein that contributes to embryonic development and is undetectable in adult tissues. An MDM4 isoform with exon 6 is frequently upregulated in cancer cells, impairing p53 tumor-suppressor function. The SSO-mediated skipping of exon 6 results in decreased MDM4 levels and reduced melanoma growth (97). Similarly, SSO targeting exon 26 of HER4 mRNA, named as SSOe26, demonstrated its capacity on HER4 isoform switching from CYT1 to CYP2. This treatment resulted in the depletion of the proliferation of breast cancer cells and tumor growth in mice xenografts (98). Furthermore, SSO targeted B-cell lymphoma (Bcl)-x pre-mRNA, which increased the Bcl-xS isoform, gaining pro-apoptotic activity, which was verified in the models of murine melanoma and in human glioma cell lines $(99,100)$.

Drug development based on targeting aberrant AS, namely small molecule splicing modulators, is an interesting approach for cancer treatment. Splicing regulators are upstream molecules that control the splicing events of multiple genes. Insight into novel target genes of the splicing regulators, can be used to manipulate the effective inhibitor(s) of these upstream molecules to suppress various downstream oncogenic spliced isoforms. However, the off-target effect, toxicity $(101,102)$ and the effects of small splicing factors interfering with the normal splicing patterns of global genes, should be considered. On the other hand, the specificity of SSO technology overcomes more than small splicing modulators by modulating AS through inhibiting only its oncogenic target which leads to effective treatment. The major problems of oligonucleotides include toxicity, instability against nucleases and delivery limitations.

\section{Conclusion}

The present review summarized the experimental evidence for and clinical relevance of the verification of significant effects of aberrant mRNA splicing of well-characterized genes with respect to CCA initiation and aggressiveness. The nine genes discussed underwent AS and revealed an intercorrelation with cholangiocarcinogenesis and progression. This information will serve as an opportunity to develop novel strategies for CCA detection and intervention. Interestingly, certain of the cancer-specific variants may serve as potential targets for CCA prognosis including $\triangle 2 \mathrm{TFF} 2$ and $\Delta 133 \mathrm{p} 53$, which demonstrate their clinical impact on patient survival. These oncogenic isoforms may be used as targets for cancer treatment, using specific antibodies, or the construction of SSOs which can modulate aberrant splicing. The regulatory machinery, including splicing factors and regulators, represents alternative targets of precision strategies, regarding the depletion of oncogenic isoforms. Finally, this summarization provides new ideas for the improvement of CCA diagnosis and treatment. Further studies should aim to investigate the unclear linkages between AS and CCA to unlock the molecular mechanisms governing AS regulation in CCA development and progression.

\section{Acknowledgements}

Not applicable.

\section{Funding}

JY was supported by The Nuresuan University research scholarship for graduate students. WK is supported by the grant from the Thailand Research Fund and Office of the Higher Education Commission providing to (grant no. TRF-MRG6080014). SJ is supported by The Foundation for Cancer Care, Siriraj Hospital, the Advanced Research on Pharmacology Fund; Siriraj Foundation (grant no. D003421) 
and the Chalermphrakiat Grant, Faculty of Medicine Siriraj Hospital, Mahidol University.

\section{Availability of data and materials}

Not applicable.

\section{Authors' contributions}

JY and WK designed, performed and wrote the literature review. SJ and SW revised the manuscript for intellectual content.

\section{Ethics approval and consent to participate}

Not applicable.

\section{Consent for publication}

Not applicable.

\section{Competing interests}

The authors declare that they have no competing interests.

\section{References}

1. Macias RI: Cholangiocarcinoma: And pharmacological Biology, Clinical management perspectives. ISRN Hepatol, 2014. https:// doi.org/10.1155/2014/828074

2. Banales JM, Cardinale V, Carpino G, Marzioni M, Andersen JB Invernizzi P, Lind GE, Folseraas T, Forbes SJ, Fouassier L, et al: Expert consensus document: Cholangiocarcinoma: current knowledge and future perspectives consensus statement from the European Network for the Study of Cholangiocarcinoma (ENS-CCA). Nat Rev Gastroenterol Hepatol 13: 261-280, 2016.

3. Sripa B and Pairojkul C: Cholangiocarcinoma: Lessons from Thailand. Curr Opin Gastroenterol 24: 349-356, 2008.

4. Thuwajit C, Thuwajit P, Kaewkes S, Sripa B, Uchida K, Miwa M and Wongkham $\mathrm{S}$ : Increased cell proliferation of mouse fibroblast $\mathrm{NIH}-3 \mathrm{~T} 3$ in vitro induced by excretory/secretory product(s) from Opisthorchis viverrini. Parasitology 129: 455-464, 2004.

5. Srivatanakul P, Ohshima H, Khlat M, Parkin M, Sukaryodhin S, Brouet I and Bartsch H: Opisthorchis viverrini infestation and endogenous nitrosamines as risk factors for cholangiocarcinoma in Thailand. Int J Cancer 48: 821-825, 1991.

6. Patel T: New insights into the molecular pathogenesis of intrahepatic cholangiocarcinoma. J Gastroenterol 49: 165-172, 2014.

7. Marks EI and Yee NS: Molecular genetics and targeted therapeutics in biliary tract carcinoma. World J Gastroenterol 22: $1335-1347,2016$

8. Rizvi S, Borad MJ, Patel T and Gores GJ: Cholangiocarcinoma: Molecular pathways and therapeutic opportunities. Semin Liver Dis 34: 456-464, 2014.

9. Goldstein D, Lemech C and Valle J: New molecular and immunotherapeutic approaches in biliary cancer. ESMO Open 2 (Suppl 1): e000152, 2017.

10. Roy B, Haupt LM and Griffiths LR: Review: Alternative splicing (AS) of genes as an approach for generating protein complexity. Curr Genomics 14: 182-194, 2013.

11. Douglas AG and Wood MJ: RNA splicing: Disease and therapy. Brief Funct Genomics 10: 151-164, 2011.

12. Ghigna $\mathrm{C}$, Valacca $\mathrm{C}$ and Biamonti G: Alternative splicing and tumor progression. Curr Genomics 9: 556-570, 2008.

13. Tazi J,Bakkour N and Stamm S: Alternative splicing and disease. Biochim Biophys Acta 1792: 14-26, 2009.

14. Venables JP: Aberrant and alternative splicing in cancer. Cancer Res 64: 7647-7654, 2004

15. Ladomery M: Aberrant alternative splicing is another hallmark of cancer. Int J Cell Biol 2013: 463786, 2013.

16. Pio R and Montuenga LM: Alternative splicing in lung cancer J Thorac Oncol 4: 674-678, 2009.
17. Martínez-Montiel N, Anaya-Ruiz M, Pérez-Santos M and Martínez-Contreras RD: Alternative splicing in breast cancer and the potential development of therapeutic tools. Genes (Basel) 8: pii: E217, 2017

18. Xiping Z, Qingshan W, Shuai Z, Hongjian Y and Xiaowen D: A summary of relationships between alternative splicing and breast cancer. Oncotarget 8: 51986-51993, 2017.

19. Liu L, Xie S, Zhang C and Zhu F: Aberrant regulation of alternative pre-mRNA splicing in hepatocellular carcinoma. Crit Rev Eukaryot Gene Expr 24: 133-149, 2014.

20. Zhang L, Liu X, Zhang $X$ and Chen R: Identification of important long non-coding RNAs and highly recurrent aberrant alternative splicing events in hepatocellular carcinoma through integrative analysis of multiple RNA-Seq datasets. Mol Genet Genomics 291: 1035-1051, 2016.

21. Ghigna C, Giordano S, Shen H, Benvenuto F, Castiglioni F, Comoglio PM, Green MR, Riva S and Biamonti G: Cell motility is controlled by SF2/ASF through alternative splicing of the Ron protooncogene. Mol Cell 20: 881-890, 2005.

22. Stallings-Mann ML, Waldmann J, Zhang Y, Miller E, Gauthier ML, Visscher DW, Downey GP, Radisky ES, Fields AP and Radisky DC: Matrix metalloproteinase induction of Raclb, a key effector of lung cancer progression. Sci Transl Med 4: 142ra95, 2012

23. Poulikakos PI, Persaud Y, Janakiraman M, Kong X, Ng C, Moriceau G, Shi H, Atefi M, Titz B, Gabay MT, et al: RAF inhibitor resistance is mediated by dimerization of aberrantly spliced BRAF(V600E). Nature 480: 387-390, 2011.

24. He C, Zhou F, Zuo Z, Cheng H and Zhou R: A global view of cancer-specific transcript variants by subtractive transcriptome-wide analysis. PLoS One 4: e4732, 2009.

25. Chen Y, Liu D, Liu P, Chen Y, Yu H and Zhang Q: Identification of biomarkers of intrahepatic cholangiocarcinoma via integrated analysis of mRNA and miRNA microarray data. Mol Med Rep 15: 1051-1056, 2017.

26. Yu Q and Stamenkovic I: Cell surface-localized matrix metalloproteinase-9 proteolytically activates TGF-beta and promotes tumor invasion and angiogenesis. Genes Dev 14: 163-176, 2000.

27. Nam K, Oh S, Lee KM, Yoo SA and Shin I: CD44 regulates cell proliferation, migration, and invasion via modulation of c-Src transcription in human breast cancer cells. Cell Signal 27: 1882-1894, 2015.

28. Saito S, Okabe H, Watanabe M, Ishimoto T, Iwatsuki M, Baba Y, Tanaka Y, Kurashige J, Miyamoto Y and Baba H: CD44v6 expression is related to mesenchymal phenotype and poor prognosis in patients with colorectal cancer. Oncol Rep 29: 1570-1578, 2013.

29. Wang J, Xiao L, Luo CH, Zhou H, Zeng L, Zhong J, Tang Y, Zhao XH, Zhao M and Zhang Y: CD44v6 promotes $\beta$-catenin and TGF- $\beta$ expression, inducing aggression in ovarian cancer cells. Mol Med Rep 11: 3505-3510, 2015.

30. Yamaguchi A, Zhang M, Goi T, Fujita T, Niimoto S, Katayama K and Hirose K: Expression of variant CD44 containing variant exon v8-10 in gallbladder cancer. Oncol Rep 7: 541-544, 2000.

31. Sosulski A, Horn H, Zhang L, Coletti C, Vathipadiekal V, Castro CM, Birrer MJ, Nagano O, Saya H, Lage K, et al: CD44 splice variant v8-10 as a marker of serous ovarian cancer prognosis. PLoS One 11: e0156595, 2016.

32. Yun KJ, Yoon KH and Han WC: Immunohistochemical study for CD44v6 in hepatocellular carcinoma and cholangiocarcinoma. Cancer Res Treat 34: 170-174, 2002.

33. Thanee M, Loilome W, Techasen A, Sugihara E, Okazaki S, Abe S, Ueda S, Masuko T, Namwat N, Khuntikeo N, et al: CD44 variant-dependent redox status regulation in liver fluke-associated cholangiocarcinoma: A target for cholangiocarcinoma treatment. Cancer Sci 107: 991-1000, 2016.

34. Liu H, Dong W, Lin Z, Lu J, Wan H, Zhou Z and Liu Z: CCN4 regulates vascular smooth muscle cell migration and proliferation. Mol Cells 36: 112-118, 2013.

35. Ono M, Inkson CA, Kilts TM and Young MF: WISP-1/CCN4 regulates osteogenesis by enhancing BMP-2 activity. J Bone Miner Res 26: 193-208, 2011.

36. Tanaka S, Sugimachi K, Saeki H, Kinoshita J, Ohga T, Shimada M, Maehara Y and Sugimachi K: A novel variant of WISP1 lacking a Von Willebrand type C module overexpressed in scirrhous gastric carcinoma. Oncogene 20: 5525-5532, 2001.

37. Tanaka S, Sugimachi K, Kameyama T, Maehara S, Shirabe K, Shimada M, Wands JR and Maehara Y: Human WISP1v, a member of the CCN family, is associated with invasive cholangiocarcinoma. Hepatology 37: 1122-1129, 2003. 
38. Wu Q, Jorgensen M, Song J, Zhou J, Liu C and Pi L: Members of the Cyr61/CTGF/NOV protein family: Emerging players in hepatic progenitor cell activation and intrahepatic cholangiocarcinoma. Gastroenterol Res Pract 2016: 2313850, 2016

39. Helps NR, Luo X, Barker HM and Cohen PT: NIMA-related kinase 2 (Nek2), a cell-cycle-regulated protein kinase localized to centrosomes, is complexed to protein phosphatase 1 . Biochem J 349: 509-518, 2000.

40. Fardilha M, Wu W, Sá R, Fidalgo S, Sousa C, Mota C, da Cruz e Silva OA and da Cruz e Silva EF: Alternatively spliced protein variants as potential therapeutic targets for male infertility and contraception. Ann N Y Acad Sci 1030: 468-478, 2004.

41. Zhong X, Guan X, Dong Q, Yang S, Liu W and Zhang L: Examining Nek2 as a better proliferation marker in non-small cell lung cancer prognosis. Tumour Biol 35: 7155-7162, 2014.

42. Wang S, Li W, Liu N, Zhang F, Liu H, Liu F, Liu J, Zhang T and Niu Y: Nek2A contributes to tumorigenic growth and possibly functions as potential therapeutic target for human breast cancer. J Cell Biochem 113: 1904-1914, 2012

43. Lai XB, Nie YQ, Huang HL, Li YF, Cao CY, Yang H, Shen B and Feng ZQ: NIMA-related kinase 2 regulates hepatocellular carcinoma cell growth and proliferation. Oncol Lett 13: $1587-1594,2017$.

44. Kokuryo T, Senga T, Yokoyama Y, Nagino M, Nimura Y and Hamaguchi M: Nek2 as an effective target for inhibition of tumorigenic growth and peritoneal dissemination of cholangiocarcinoma. Cancer Res 67: 9637-9642, 2007.

45. Wang Y, Shen H, Yin Q, Zhang T, Liu Z, Zhang W and Niu Y: Effect of NIMA-related kinase $2 B$ on the sensitivity of breast cancer to paclitaxel in vitro and vivo. Tumour Biol 39 1010428317699754,2017

46. Xue L, Aihara E, Podolsky DK, Wang TC and Montrose MH: In vivo action of trefoil factor 2 (TFF2) to speed gastric repair is independent of cyclooxygenase. Gut 59: 1184-1191, 2010.

47. Kosriwong K, Menheniott TR, Giraud AS, Jearanaikoon P, Sripa B and Limpaiboon T: Trefoil factors: Tumor progression markers and mitogens via EGFR/MAPK activation in cholangiocarcinoma. World J Gastroenterol 17: 1631-1641, 2011

48. Kamlua S, Patrakitkomjorn S, Jearanaikoon P, Menheniott TR, Giraud AS and Limpaiboon T: A novel TFF2 splice variant ( $\triangle \mathrm{EX} 2 \mathrm{TFF} 2)$ correlates with longer overall survival time in cholangiocarcinoma. Oncol Rep 27: 1207-1212, 2012.

49. Kim M, Grimmig T, Grimm M, Lazariotou M, Meier E, Rosenwald A, Tsaur I, Blaheta R, Heemann U, Germer CT, et al: Expression of Foxp3 in colorectal cancer but not in Treg cells correlates with disease progression in patients with colorectal cancer. PLoS One 8: e53630, 2013.

50. Harada K, Shimoda S, Kimura Y, Sato Y, Ikeda H, Igarashi S, Ren XS, Sato H and Nakanuma Y: Significance of immunoglobulin G4 (IgG4)-positive cells in extrahepatic cholangiocarcinoma: Molecular mechanism of $\mathrm{IgG} 4$ reaction in cancer tissue. Hepatology 56: 157-164, 2012.

51. Ebert LM, Tan BS, Browning J, Svobodova S, Russell SE, Kirkpatrick N, Gedye C, Moss D, Ng SP, MacGregor D, et al The regulatory $\mathrm{T}$ cell-associated transcription factor FoxP3 is expressed by tumor cells. Cancer Res 68: 3001-3009, 2008

52 . Hu W, Feng Z and Levine AJ: The regulation of multiple p53 stress responses is mediated through MDM2. Genes Cancer 3 199-208, 2012

53. Khoury MP and Bourdon JC: The isoforms of the p53 protein Cold Spring Harb Perspect Biol 2: a000927, 2010.

54. Surget S, Khoury MP and Bourdon JC: Uncovering the role of p53 splice variants in human malignancy: A clinical perspective. Onco Targets Ther 7: 57-68, 2013

55. Arsic N, Gadea G, Lagergvist EL, Busson M, Cahuzac N, Brock C, Hollande F, Gire V, Pannequin J and Roux P: The p53 isoform $\Delta 133 \mathrm{p} 53 \beta$ promotes cancer stem cell potential. Stem Cell Reports 4: 531-540, 2015.

56. Arsic N, Ho-Pun-Cheung A, Evelyne C, Assenat E, Jarlier M, Anguille C, Colard M, Pezet M, Roux P and Gadea G: The p53 isoform delta133p53ß regulates cancer cell apoptosis in a RhoB-dependent manner. PLoS One 12: e0172125, 2017.

57. Della Torre G, Pasquini G, Pilotti S, Alasio L, Civelli E, Cozzi G, Milella M, Salvetti M, Pierotti MA and Severini A: TP53 mutations and mdm2 protein overexpression in cholangiocarcinomas. Diagn Mol Pathol 9: 41-46, 2000.

58. Tullo A, D'Erchia AM, Honda K, Kelly MD, Habib NA, Saccone $\mathrm{C}$ and Sbisà E: New p53 mutations in hilar cholangiocarcinoma. Eur J Clin Invest 30: 798-803, 2000.

59. Liu XF, Zhang H, Zhu SG, Zhou XT, Su HL, Xu Z and Li SJ: Correlation of $\mathrm{p} 53$ gene mutation and expression of P53 protein in cholangiocarcinoma. World J Gastroenterol 12: 4706-4709, 2006
60. Nutthasirikul N, Limpaiboon T, Leelayuwat C, Patrakitkomjorn S and Jearanaikoon P: Ratio disruption of the $\Delta 133$ p53 and TAp53 isoform equilibrium correlates with poor clinical outcome in intrahepatic cholangiocarcinoma. Int J Oncol 42: 1181-1188, 2013.

61. Nutthasirikul N, Hahnvajanawong C, Techasen A, Limpaiboon T, Leelayuwat C, Chau-In S and Jearanaikoon P: Targeting the $\Delta 133 \mathrm{p} 53$ isoform can restore chemosensitivity in 5-fluorouracil-resistant cholangiocarcinoma cells. Int J Oncol 47: 2153-2164, 2015.

62. Liu K, Zang Y, Guo X, Wei F, Yin J, Pang L and Chen D: The $\Delta 133$ p53 isoform reduces wtp53-induced stimulation of DNA Pol $\gamma$ activity in the presence and absence of D4T. Aging Dis 8: 228-239, 2017.

63. David CJ, Chen M, Assanah M, Canoll P and Manley JL: HnRNP proteins controlled by c-Myc deregulate pyruvate kinase mRNA splicing in cancer. Nature 463: 364-368, 2010.

64. Liu WR, Tian MX, Yang LX, Lin YL, Jin L, Ding ZB, Shen YH, Peng YF, Gao DM, Zhou J, et al: PKM2 promotes metastasis by recruiting myeloid-derived suppressor cells and indicates poor prognosis for hepatocellular carcinoma. Oncotarget 6: 846-861, 2015.

65. Li C, Zhao Z, Zhou Z and Liu R: PKM2 promotes cell survival and invasion under metabolic stress by enhancing Warburg effect in pancreatic ductal adenocarcinoma. Dig Dis Sci 61: 767-773, 2016.

66. Lu W, Cao Y, Zhang Y, Li S, Gao J, Wang XA, Mu J, Hu YP, Jiang L, Dong P, et al: Up-regulation of PKM2 promote malignancy and related to adverse prognostic risk factor in human gallbladder cancer. Sci Rep 6: 26351, 2016.

67. Yu G, Yu W, Jin G, Xu D, Chen Y, Xia T, Yu A, Fang W, Zhang X, $\mathrm{Li} \mathrm{Z}$, et al: $\mathrm{PKM} 2$ regulates neural invasion of and predicts poor prognosis for human hilar cholangiocarcinoma. Mol Cancer 14: $193,2015$.

68. Kotani M, Tanaka I, Ogawa Y, Suganami T, Matsumoto T, Muro S, Yamamoto Y, Sugawara A, Yoshimasa Y, Sagawa N, et al: Multiple signal transduction pathways through two prostaglandin E receptor EP3 subtype isoforms expressed in human uterus. J Clin Endocrinol Metab 85: 4315-4322, 2000.

69. Ma J, Chen M, Xia SK, Shu W, Guo Y, Wang YH, Xu Y, Bai XM, Zhang L, Zhang H, et al: Prostaglandin E2 promotes liver cancer cell growth by the upregulation of FUSE-binding protein 1 expression. Int J Oncol 42: 1093-1104, 2013.

70. Kotelevets L, Foudi N, Louedec L, Couvelard A, Chastre E and Norel X: A new mRNA splice variant coding for the human EP3-I receptor isoform. Prostaglandins Leukot Essent Fatty Acids 77: 195-201, 2007.

71. Du M, Shi F, Zhang H, Xia S, Zhang M, Ma J, Bai X, Zhang L, Wang Y, Cheng S, et al: Prostaglandin E2 promotes human cholangiocarcinoma cell proliferation, migration and invasion through the upregulation of $\beta$-catenin expression via EP3-4 receptor. Oncol Rep 34: 715-726, 2015.

72. Uthaisar K, Vaeteewoottacharn K, Seubwai W, Talabnin C, Sawanyawisuth K, Obchoei S, Kraiklang R, Okada S and Wongkham S: Establishment and characterization of a novel human cholangiocarcinoma cell line with high metastatic activity. Oncol Rep 36: 1435-1446, 2016.

73. Neeb A, Hefele S, Bormann S, Parson W, Adams F, Wolf P, Miernik A, Schoenthaler M, Kroenig M, Wilhelm K, et al: Splice variant transcripts of the anterior gradient 2 gene as a marker of prostate cancer. Oncotarget 5: 8681-8689, 2014.

74. Yosudjai J, Inpad C, Chomwong S, Dana P, Sawanyawisuth K, Phimsen S, Wongkham S, Jirawatnotai S and Kaewkong W: An aberrantly spliced isoform of anterior gradient-2, AGR2 $2 \mathrm{H}$ promotes migration and invasion of cholangiocarcinoma cell. Biomed Pharmacother 107: 109-116, 2018

75. Yang $Y$ and Walsh CE: Spliceosome-mediated RNA trans-splicing. Mol Ther 12: 1006-1012, 2005.

76. Mansfield SG, Chao $H$ and Walsh CE: RNA repair using spliceosome-mediated RNA trans-splicing. Trends Mol Med 10: 263-268, 2004

77. He X, Liao J, Liu F, Yan J, Yan J, Shang H, Dou Q, Chang Y, Lin J and Song Y: Functional repair of p53 mutation in colorectal cancer cells using trans-splicing. Oncotarget 6: 2034-2045, 2015.

78. He X, Liu F, Yan J, Zhang Y, Yan J, Shang H, Dou Q, Zhao Q and Song Y: Trans-splicing repair of mutant p53 suppresses the growth of hepatocellular carcinoma cells in vitro and in vivo. Sci Rep 5: 8705, 2015

79. Gout S, Brambilla E, Boudria A, Drissi R, Lantuejoul S, Gazzeri $S$ and Eymin B: Abnormal expression of the pre-mRNA splicing regulators SRSF1, SRSF2, SRPK1 and SRPK2 in non small cell lung carcinoma. PLoS One 7: e46539, 2012. 
80.Karni R, de Stanchina E, Lowe SW, Sinha R, Mu D and Krainer AR: The gene encoding the splicing factor SF2/ASF is a proto-oncogene. Nat Struct Mol Biol 14: 185-193, 2007.

81. Loilome W, Yongvanit P, Wongkham C, Tepsiri N, Sripa B, Sithithaworn P, Hanai S and Miwa M: Altered gene expression in Opisthorchis viverrini-associated cholangiocarcinoma in hamster model. Mol Carcinog 45: 279-287, 2006.

82. Cretu C, Schmitzová J, Ponce-Salvatierra A, Dybkov O, De Laurentiis EI, Sharma K, Will CL, Urlaub H, Lührmann R and Pena V: Molecular Architecture of SF3b and Structural Consequences of Its Cancer-Related Mutations. Mol Cell 64: 307-319, 2016

83. Darman RB, Seiler M, Agrawal AA, Lim KH, Peng S, Aird D, Bailey SL, Bhavsar EB, Chan B, Colla S, et al: Cancer-Associated SF3B1 Hotspot Mutations Induce Cryptic 3 Splice Site Selection through Use of a Different Branch Point. Cell Reports 13: 1033-1045, 2015.

84. Alsafadi S, Houy A, Battistella A, Popova T, Wassef M, Henry E, Tirode F, Constantinou A, Piperno-Neumann S, Roman-Roman S, et al: Cancer-associated SF3B1 mutations affect alternative splicing by promoting alternative branchpoint usage. Nat Commun 7: 10615, 2016

85. Furney SJ, Pedersen M, Gentien D, Dumont AG, Rapinat A, Desjardins L, Turajlic S, Piperno-Neumann S, de la Grange P, Roman-Roman S, et al: SF3B1 mutations are associated with alternative splicing in uveal melanoma. Cancer Discov 3 : 1122-1129, 2013.

86. Maguire SL, Leonidou A, Wai P, Marchiò C, Ng CK, Sapino A, Salomon AV, Reis-Filho JS, Weigelt B and Natrajan RC: SF3B1 mutations constitute a novel therapeutic target in breast cancer J Pathol 235: 571-580, 2015

87.Fu X, Tian M, Gu J, Cheng T, Ma D, Feng L and Xin X: SF3B1 mutation is a poor prognostic indicator in luminal $\mathrm{B}$ and progesterone receptor-negative breast cancer patients. Oncotarget 8: 115018-115027, 2017

88. Woolard J, Vousden W,Moss SJ,Krishnakumar A, Gammons MV, NowakDG,DixonN,MicklefieldJ,SpannhoffA,BedfordMT,etal: Borrelidin modulates the alternative splicing of VEGF in favour of anti-angiogenic isoforms. Chem Sci (Camb) 2011: 273-278, 2011.

89. Kaida D, Motoyoshi H, Tashiro E, Nojima T, Hagiwara M, IshigamiK, Watanabe H,Kitahara T, Yoshida T,NakajimaH,etal: Spliceostatin A targets SF3b and inhibits both splicing and nuclear retention of pre-mRNA. Nat Chem Biol 3: 576-583, 2007.

90. Folco EG, Coil KE and Reed R: The anti-tumor drug E7107 reveals an essential role for SF3b in remodeling U2 snRNP to expose the branch point-binding region. Genes Dev 25: 440-444, 2011.

91. Roybal GA and Jurica MS: Spliceostatin A inhibits spliceosome assembly subsequent to prespliceosome formation. Nucleic Acids Res 38: 6664-6672, 2010.

92. Satoh T and Kaida D: Upregulation of p27 cyclin-dependent kinase inhibitor and a C-terminus truncated form of p27 contributes to G1 phase arrest. Sci Rep 6: 27829, 2016.
93. Furumai R, Uchida K, Komi Y, Yoneyama M, Ishigami K, Watanabe H, Kojima S and Yoshida M: Spliceostatin A blocks angiogenesis by inhibiting global gene expression including VEGF. Cancer Sci 101: 2483-2489, 2010

94. Radhakrishnan A, Nanjappa V, Raja R, Sathe G, Chavan S, Nirujogi RS, Patil AH, Solanki H, Renuse S, Sahasrabuddhe NA, et al: Dysregulation of splicing proteins in head and neck squamous cell carcinoma. Cancer Biol Ther 17: 219-229, 2016.

95. Araki S, Dairiki R, Nakayama Y, Murai A, Miyashita R, Iwatani M, Nomura T and Nakanishi O: Inhibitors of CLK protein kinases suppress cell growth and induce apoptosis by modulating pre-mRNA splicing. PLoS One 10: e0116929, 2015.

96. Massiello A, Salas A, Pinkerman RL, Roddy P, Roesser JR and Chalfant CE: Identification of two RNA cis-elements that function to regulate the 5' splice site selection of Bcl-x pre-mRNA in response to ceramide. J Biol Chem 279: 15799-15804, 2004.

97. Dewaele M, Tabaglio T, Willekens K, Bezzi M, Teo SX, Low DH, Koh CM, Rambow F, Fiers M, Rogiers A, et al: Antisense oligonucleotide-mediated MDM4 exon 6 skipping impairs tumor growth. J Clin Invest 126: 68-84, 2016.

98. Nielsen TO, Sorensen S, Dagnæs-Hansen F, Kjems J and Sorensen BS: Directing HER4 mRNA expression towards the CYT2 isoform by antisense oligonucleotide decreases growth of breast cancer cells in vitro and in vivo. Br J Cancer 108: 2291-2298, 2013.

99. Bauman JA, Li SD, Yang A, Huang L and Kole R: Anti-tumor activity of splice-switching oligonucleotides. Nucleic Acids Res 38: 8348-8356, 2010.

100. Li Z, Li Q, Han L, Tian N, Liang Q, Li Y, Zhao X, Du C and Tian Y: Pro-apoptotic effects of splice-switching oligonucleotides targeting Bcl-x pre-mRNA in human glioma cell lines. Oncol Rep 35: 1013-1019, 2016.

101.Eskens FA, Ramos FJ, Burger H, O'Brien JP, Piera A, de Jonge MJ, Mizui Y, Wiemer EA, Carreras MJ, Baselga J, et al: Phase I pharmacokinetic and pharmacodynamic study of the first-in-class spliceosome inhibitor E7107 in patients with advanced solid tumors. Clin Cancer Res 19: 6296-6304, 2013.

102. Hong DS, Kurzrock R, Naing A, Wheler JJ, Falchook GS, Schiffman JS, Faulkner N, Pilat MJ, O'Brien J and LoRusso P: A phase I, open-label, single-arm, dose-escalation study of E7107, a precursor messenger ribonucleic acid (pre-mRNA) splicesome inhibitor administered intravenously on days 1 and 8 every 21 days to patients with solid tumors. Invest New Drugs 32: 436-444, 2014

This work is licensed under a Creative Commons Attribution-NonCommercial-NoDerivatives 4.0 International (CC BY-NC-ND 4.0) License. 